\title{
Transitions between frailty states among community-dwelling older people: A systematic review and meta-analysis.
}

Gotaro Kojima, $\mathrm{MD}^{1}$; Yu Taniguchi, $\mathrm{PhD}^{2}$; Steve Iliffe, FRCGP ${ }^{1}$; Stephen Jivraj, $\mathrm{PhD}^{3}$; Kate Walters, $\mathrm{PhD}^{1}$.

1 Department of Primary Care and Population Health, University College London, London, UK

2 Research Team for Social Participation and Community Health, Tokyo Metropolitan Institute of Gerontology, Tokyo, Japan.

3 Department of Epidemiology and Public Health, University College London, London, UK

\begin{abstract}
Frailty is a well-established risk factor for adverse health outcomes. However, little is known about the dynamic nature of frailty and the extent it can improve. The purposes of this study were to systematically search for studies examining frailty transitions over time among community-dwelling older people, and to synthesise pooled frailty transitions rates. Four electronic databases (Medline, Embase, PsycINFO and CINAHL) were searched in July 2018. Inclusion criteria were: prospective design, community-dwelling older people with mean age $\geq 60$, using 5 -item frailty phenotype criteria to define three states: robust, prefrail and frail and the numbers of participants with 9 frailty transition patterns based on frailty status at baseline and follow-up. Exclusion criteria were: selected populations, using fewer than 5 frailty phenotype criteria. Two investigators independently screened 504 studies for eligibility and identified 16 studies for this review. Data were extracted by the two investigators independently. Pooled rates of frailty transition patterns were calculated by random-effects meta-analysis. Among 42,775 community-dwelling older people from 16 studies with a mean follow-up of 3.9 years (range: $1-10$ years), $13.7 \%(95 \% \mathrm{CI}=11.7-15.8 \%)$ improved, $29.1 \%(95 \% \mathrm{CI}=25.9-32.5 \%)$ worsened and $56.5 \%(95 \% \mathrm{CI}=54.2-58.8 \%)$ maintained the same frailty status. Among those who were robust at baseline, pooled rates of remaining robust or transitioning to prefrail and frail were $54.0 \%(95 \% \mathrm{CI}=48.8-59.1 \%)$, $40.6 \%(95 \% \mathrm{CI}=36.7-44.7 \%)$ and $4.5 \%(95 \% \mathrm{CI}=3.2-6.1 \%)$, respectively. Among those who were prefrail at baseline, corresponding rates to robust, prefrail and frail were $23.1 \%$ $(95 \% \mathrm{CI}=18.8-27.6 \%), 58.2 \%(95 \% \mathrm{CI}=55.6-60.7 \%)$ and $18.2 \%(95 \% \mathrm{CI}=14.9-21.7 \%)$, respectively. Among those who were frail at baseline, pooled rates of transitioning to robust, prefrail and remaining frail were $3.3 \%(95 \% \mathrm{CI}=1.6-5.5 \%), 40.3 \%(95 \% \mathrm{CI}=34.6-46.1 \%)$ and $54.5 \%(95 \% \mathrm{CI}=47.6-61.3 \%)$, respectively. Stratified and meta-regression analyses showed age, gender and follow-up period were associated with frailty transition patterns. Older people make dynamic changes in their frailty status. Given that while one quarter of prefrail older people improved to robust only $3 \%$ of frail older people did, early interventions should be considered.
\end{abstract}

Keywords: Frailty; Frail Elderly; Transition; change; Systematic review; Meta-analysis. 


\section{INTRODUCTION}

Frailty is now a well-established risk factor for adverse health outcomes in later life,(Clegg et al., 2013; Morley et al., 2013) such as falling,(Kojima, 2015a; Kojima et al., 2015) fracture,(Kojima, 2016a, 2017b) emergency department visits,(Kojima, 2018a) hospitalisation,(Kojima, 2016b) nursing home placement,(Kojima, 2015b, 2018b) disability,(Kojima, 2017a, 2018d) dementia,(Kojima, 2016b; Kojima et al., 2017b) poor quality of life(Kojima et al., 2016a; Kojima et al., 2016b) and death.(Kojima, 2018c; Kojima et al., 2018b; Kojima et al., 2018c) While there is as yet no internationally agreed definition, the concept of frailty has been broadly accepted as a multisystem dysregulation of homeostatic mechanisms marked by reduced physiological reserve and increased vulnerability, as a result of age-related deficit accumulation.(Clegg et al., 2013; Morley, 2017) Among various definitions and criteria proposed to operationalise frailty, the most widely used is the "frailty phenotype".(Buta et al., 2016) Fried and colleagues using the Cardiovascular Health Study cohort described it as a clinical syndrome, with the following five physical components: unintentional weight loss, weakness, slow gait speed, exhaustion and low physical activity.(Fried et al., 2001) Those who met three or more components were defined as frail, those 1 or 2 components as prefrail and those without any were defined as robust.(Fried et al., 2001) This frailty phenotype has been validated and replicated in other population-based studies.(Buta et al., 2016)

Given the tremendous impacts on older people, their families and society, frailty has attracted increasing scientific attention, especially in the last two decades.(Clegg et al., 2013) In the context of ongoing global population ageing the growing number of frail older people is an emerging major public health challenge for current healthcare systems.(Cesari et al., 2016) While there is mounting evidence regarding frailty and our knowledge about frailty has dramatically improved,(Clegg et al., 2013) relatively little is known about transitions of frailty status in older people. Although advanced age is a strong risk factor,(Collard et al., 2012; Kojima et al., 2017a) frailty is not an inevitable part of ageing and not an irreversible one-way process to disability or death, but a dynamic process involving improvement as well as natural progression.(Clegg et al., 2013) Gill et al. measured frailty status defined by the frailty phenotype (robust, prefrail, frail) four times, that is, every 18 months over a total of 54 months for 754 nondisabled US community-dwelling older people.(Gill et al., 2006) They demonstrated that more than half (57.6\%) made at least one frailty transition and that participants were more likely to transition to worse frailty status (up to $43.3 \%$ ) but also some improved their frailty status (up to $23.0 \%$ ).(Gill et al., 2006)

It is imperative to enhance our understanding of the course of frailty in order to predict trends in frailty transitions. Insight into how the frailty status of older people evolves over time will also help in the design of appropriate frailty interventions and in the identification of optimal target populations to prevent or delay progression. However there is a paucity of evidence in the literature on overall frailty transitions. For example, the percentage of robust people that become prefrail or frail, or how many prefrail people improve to robust, are still to be elucidated. These findings will contribute to the broader literature on frailty and have a significant impact on the future directions of this research field, especially from clinical and public health standpoints. The objectives of this review are to systematically search for longitudinal cohort studies examining frailty transitions over time, and to synthesise pooled rates of transitions between frailty states by using meta-analysis. 


\section{METHOD}

\subsection{Data source and search strategy}

A systematic search of the literature was conducted by one investigator (GK) for studies published from 2000 up to July 2018 using MEDLINE, Embase, PsycINFO and CINAHL Plus, based on a protocol (PROSPERO registration number CRD42018103181) developed in accordance with PRIMSA(Moher et al., 2009) and MOOSE(Stroup et al., 2000) statements. The publication period was chosen because the frailty phenotype, which we focus on in the current review, was first published in 2001.(Fried et al., 2001) We used a Medical Subjective Heading $(\mathrm{MeSH})$ and text terms to search for studies published in 2000 or later, with explosion function if available and without language restriction. The search terms were: [Frailty (MeSH) OR Frail elderly (MeSH) OR Frailty syndrome (MeSH) OR frailty] AND "transition*". We conducted a supplementary search in the same four databases, using "progression*" OR "outcome*" OR "prognosis" OR "course*" in titles along with the frailtyrelated search terms that were initially used.

We also hand-searched reference lists of included studies and related papers and performed forward citation tracking of the included studies. We further attempted to identify prospective studies examining incident frailty, as these studies theoretically have frailty status data at two time points, by conducting a pubmed search using "incident frailty" and "incidence of frailty" and by scrutinising two previous review papers regarding predictors of frailty.(Feng et al., 2017; Mello Ade et al., 2014) We also contacted corresponding authors for additional data on baseline and follow-up frailty status.

\subsection{Study Selection}

Inclusion criteria were: (1) prospective design, (2) community-dwelling older people with a mean age of 60 or more, (3) use of the full 5-item frailty phenotype criteria (or modified versions of it) to define three frailty states: robust, prefrail and frail, as meeting Fried's 0, 1-2, and 3-5 criteria and (4) the numbers of participants with 9 transition types based on frailty status at baseline and follow-up: e.g. from robust to robust, from robust to prefrail, from robust to frail, etc.

Studies were excluded if they (1) used selected populations, such as those with a specific disease or medical condition, (2) used the frailty phenotype criteria but with 4 items, substituting subjective measures, such as self-reported questionnaire score on physical function, for gait speed and grip strength(Kojima, 2017c) or 5-point score instead of three categories (robust, prefrail and frail) (3) were conference abstracts, randomised controlled trials, reviews, editorials, comments or dissertations. Titles, abstracts and full-texts of studies identified by the review were screened for eligibility by two investigators (GK and YT) independently using the inclusion and exclusion criteria. The corresponding authors were contacted for clarification or additional data where necessary. If frailty status was measured at more than two time points, transition between the first and second time points was used. If two or more studies used the same cohort, the study with the largest number of the participants was used. Any disagreements were resolved by discussion.

\subsection{Data Extraction}

Data retrieved from the included studies were; first author, study/cohort name if any, publication year, location, sample size, proportion of female participants, mean age, age range, follow-up period and the number of participants for each frailty transition type. The data were extracted by one investigator (GK) and independently confirmed by another (YT). 


\subsection{Methodological Quality Assessment}

Eligible studies were assessed for methodological quality by two investigators (GK and YT) using the 9-item Newcastle-Ottawa scale for cohort studies.(Wells et al.) This scale is designed to evaluate a cohort study over the domains of selection, compatibility and outcome. To tailor the compatibility for our research question, the most important factors to control were defined as age and gender and additional factors to control included smoking, alcohol, socioeconomic status and education. In the outcome, percentage of loss to follow-up unlikely to introduce bias was defined as $10 \%$ or less. If a study met 5 items or more of 9 , or more than half of relevant items if there are any items not applicable, it was considered to have adequate methodological quality.

\subsection{Statistical Analysis}

We separately calculated pooled rates of 3 different transition patterns that (1) improved (frail to prefrail, frail to robust, prefrail to robust), worsened (robust to prefrail, robust to frail, prefrail to frail) and did not change (robust to robust, prefrail to prefrail, frail to frail) frailty status over time. The transition rates of each of the included studies were combined using a random-effects meta-analysis. A random-effects model was chosen a priori due to expected high heterogeneity from differences in study population, mean age, gender proportion and follow-up period. Heterogeneity was quantified by using $\mathrm{I}^{2}$ statistic. Freeman-Tukey double arcsine transformation was used, to avoid bias toward a higher frailty transition rate by excluding studies with a zero frailty transition rate.(Nyaga et al., 2014) Publication bias was examined graphically by funnel plots and statistically by Begg's rank correlation test and Egger's linear regression test.

Because frailty is a strong predictor of mortality,(Kojima, 2018c; Kojima et al., 2018b) as a supplementary analysis we repeated another set of meta-analyses for the same three frailty transition patterns as above including studies that provided data on transitions to death (i.e. robust to death, prefrail to death and frail to death) as well. The frailty transitions of improvement (prefrail to robust, frail to robust, frail to prefrail) and remaining unchanged (robust to robust, prefrail to prefrail, frail to frail) are the same, but the worsening pattern also includes any frailty transitions to death.

According to previous studies, factors associated with frailty transition patterns include baseline frailty status, age, gender and follow-up period.(Espinoza et al., 2012; Trevisan et al., 2017) Therefore, we conducted additional supplementary analyses to explore how these factors are associated with frailty transitions. The gender-stratified rates of three frailty transition patterns (worsening, improving and staying the same) were re-calculated and compared between female-only and male-only samples. Then, pooled rates of nine frailty transition types by baseline frailty status (1. robust to robust, 2. robust to prefrail, 3. robust to frail, 4. prefrail to robust, 5. prefrail to prefrail, 6. prefrail to frail, 7. frail to robust, 8. frail to prefrail and 9. frail to frail) were calculated. These meta-analyses were repeated in femaleonly and male-only samples, and the transition rates were compared by gender. Randomeffects meta-regression analyses were conducted by using mean age, proportion of female participants and follow-up period as modulators to examine how much variability of the pooled frailty transition rates could be explained by these factors. A meta-analysis of the three frailty transition patterns was repeated stratified by study location (Europe, US and the others).

StataSE 14 (StataCorp LP, College Station, Texas, USA) was used for all analyses except for a meta-regression analysis, for which Comprehensive Meta-Analysis (version 3.3, Biostat, 
New Jersey, US) was used. A 2-tailed significance level was set at p value of less than 0.05.

\section{RESULTS}

\subsection{Selection Processes}

The initial search revealed 842 studies, and 8 additional studies were found from other sources. The supplementary search did not find any additional studies to be included. After removing duplicates, 504 studies were screened for titles and abstracts, leaving 24 studies for full-text assessment. Eight studies were excluded because of missing data necessary for metaanalysis, which were not provided by the corresponding authors upon request $(n=5)$, used the same cohorts $(n=2)$ or used a 4 -item frailty phenotype $(n=1)$. Finally 16 studies, incorporating 42,775 participants from 16 cohorts with a mean follow-up of 3.9 years (range 1-10 years), were included in this review. Characteristics of the included studies were summarised in Table 1. All studies were considered to have adequate methodological quality (the Newcastle-Ottawa scale score ranged 6-9, mean 7.7) except for two(Gill et al., 2006; Xue, 2011) that provided data of frailty transition descriptively so that it was not possible to assess properly using the Newcastle-Ottawa scale.

\subsection{Meta-analysis of frailty transition rates}

\subsubsection{Three frailty transition patterns}

In our pooled analysis of data from 16 studies, $13.7 \%(95 \%$ confidence interval $(\mathrm{CI})=11.7-$ $15.8 \%)$ improved, $29.1 \%(95 \% \mathrm{CI}=25.9-32.5 \%)$ worsened and $56.5 \%(95 \% \mathrm{CI}=54.2-58.8 \%)$ maintained the same frailty status over a mean of 3.9 years. (Table 2). A high degree of heterogeneity was observed in the three transition patterns ( $\mathrm{I}^{2}$ values $=97.0 \%, 98.0 \%$ and 94.9\%, respectively) Forest plots are shown in Figure 2 A-C. Of the 16 studies, 11 and 9 studies provided data of female-only and male-only participants, respectively (studies including female only,(Ensrud et al., 2010; Kim et al., 2017; Xue, 2011) male only,(Pollack et al., 2017) or mixed-gender studies with gender-stratified data available(Borrat-Besson et al., 2013; Castrejon-Perez et al., 2017; Garcia-Esquinas et al., 2016; Kojima et al., 2018a; Lee et al., 2014; Saum et al., 2017; Trevisan et al., 2017; Yu et al., 2015)). Among female participants, $14.7 \%(95 \% \mathrm{CI}=12.3-17.4 \%)$ improved, $28.5 \%(95 \% \mathrm{CI}=24.4-32.7 \%)$ worsened and $55.9 \%(95 \% \mathrm{CI}=54.0-57.8 \%)$ maintained the same frailty status. Among male participants, $12.6 \%(95 \% \mathrm{CI}=9.9-15.6 \%)$ improved, $28.3 \%(95 \% \mathrm{CI}=24.9-31.2 \%)$ worsened and $59.1 \%(95 \% \mathrm{CI}=57.2-61.1 \%)$ maintained the same frailty status. The high degree of heterogeneity remained after stratifying by gender. $\left(\mathrm{I}^{2}=83.8 \%-97.6 \%\right)$ Although there are no significant differences in frailty transition rates of improvement and worsening by gender, men were significantly more likely to maintain the same frailty status than women $(59.1 \%$ versus $55.9 \%$, $p$ for difference $=0.02$ ). (Figure 3 and Table 2) In stratified analyses by location, the high heterogeneity remained; $12.4 \%\left(95 \% \mathrm{CI}=9.0-16.2 \%, \mathrm{I}^{2}=98.1 \%\right), 10.9 \%$ $\left(95 \% \mathrm{CI}=9.6-12.3 \%, \mathrm{I}^{2}=72.4 \%\right)$ and $18.7 \%\left(95 \% \mathrm{CI}=14.3-23.5 \%, \mathrm{I}^{2}=95.0 \%\right)$ improved; $30.5 \%$ $\left(95 \% \mathrm{CI}=24.6-36.7 \%, \mathrm{I}^{2}=98.7 \%\right), 31.5 \%\left(95 \% \mathrm{CI}=25.0-38.5 \%, \mathrm{I}^{2}=98.0 \%\right)$ and $24.8 \%$ $\left(95 \% \mathrm{CI}=19.7-30.4 \%, \mathrm{I}^{2}=95.4 \%\right)$ worsened; $56.7 \%\left(95 \% \mathrm{CI}=53.9-59.6 \%, \mathrm{I}^{2}=93.2 \%\right), 56.7 \%$ $\left(95 \% \mathrm{CI}=49.9-63.4 \%, \mathrm{I}^{2}=97.7 \%\right)$ and $56.4 \%\left(95 \% \mathrm{CI}=53.1-59.6 \%, \mathrm{I}^{2}=82.3 \%\right)$ stayed the same. There was no evidence of publication bias based on funnel plots, Begg's and Egger's tests.

\subsubsection{Nine frailty transition patterns}

The nine frailty transition patterns of 16 studies were pooled by baseline frailty status. 
Among those who were robust at baseline, pooled rates of remaining robust or transitioning to prefrail and frail over a mean of 3.9 years were $54.0 \%\left(95 \% \mathrm{CI}=48.8-59.1 \%, \mathrm{I}^{2}=98.0 \%\right)$, $40.6 \%\left(95 \% \mathrm{CI}=36.7-44.7 \%, \mathrm{I}^{2}=96.6 \%\right)$ and $4.5 \%\left(95 \% \mathrm{CI}=3.2-6.1 \%, \mathrm{I}^{2}=95.1 \%\right)$, respectively. Among those who were prefrail at baseline, corresponding rates to robust, prefrail and frail at follow-up were $23.1 \%\left(95 \% \mathrm{CI}=18.8-27.6 \%, \mathrm{I}^{2}=97.8 \%\right), 58.2 \%$ $\left(95 \% \mathrm{CI}=55.6-60.7 \%, \mathrm{I}^{2}=90.2 \%\right)$ and $18.2 \%\left(95 \% \mathrm{CI}=14.9-21.7 \%, \mathrm{I}^{2}=96.8 \%\right)$, respectively. Among those who were frail at baseline, pooled rates of transitioning to robust, prefrail and remaining frail at follow-up were 3.3\% $\left(95 \% \mathrm{CI}=1.6-5.5 \%, \mathrm{I}^{2}=81.1 \%\right), 40.3 \%(95 \% \mathrm{CI}=34.6$ $\left.46.1 \%, \mathrm{I}^{2}=86.5 \%\right)$ and $54.5 \%\left(95 \% \mathrm{CI}=47.6-61.3 \%, \mathrm{I}^{2}=90.5 \%\right)$, respectively. There was a high degree of heterogeneity in all analyses.

Pooled rates of the nine frailty transition patterns were calculated by gender as well for eleven female-only and nine male-only data sets, and summarised in Figure 3 along with the overall sample. The high degree of heterogeneity remained in all gender-stratified analyses $\left(\mathrm{I}^{2}=60.5 \%-99.5 \%\right)$. Among robust participants, men were significantly more likely to remain robust (men $60.5 \%$ versus women $52.5 \%, \mathrm{p}=0.04$ ) and women were significantly more likely to transition to prefrail (women $42.4 \%$ versus men $35.5 \%, \mathrm{p}=0.04$ ). (Table 2)

\subsubsection{Three and nine frailty transition patterns including death at follow-up}

Nine studies provided data of frailty transitions including death at follow-up.(Alencar et al., 2015; Borrat-Besson et al., 2013; Espinoza et al., 2012; Gill et al., 2006; Lee et al., 2014; Ottenbacher et al., 2009; Pollack et al., 2017; Trevisan et al., 2017; Xue, 2011) Pooled rates of improving, worsening (including death) and maintaining the same frailty transitions over a mean of 4.0 years were $10.9 \%(95 \% \mathrm{CI}=8.0-14.2 \%), 37.8 \%(95 \% \mathrm{CI}=25.6-48.5 \%)$ and $50.3 \%$ $(95 \% \mathrm{CI}=41.9-58.7 \%)$, respectively. Among participants who were robust, prefrail and frail at baseline, $6.8 \%, 13.4 \%$ and $32.5 \%$ died by the follow-up, respectively. Among those who were frail at baseline, $2.0 \%(95 \% \mathrm{CI}=0.2-4.8 \%)$ changed to robust, $25.3 \%(95 \% \mathrm{CI}=16.6-35.2 \%)$ changed to prefrail, $33.6 \%(95 \% \mathrm{CI}=22.0-46.2 \%)$ remained frail and $32.5 \%(95 \% \mathrm{CI}=17.3-$ 49.8\%) died. (Table 2)

\subsection{Meta-regression analysis}

Mean age, proportion of female participants and follow-up period of the included studies were separately entered as modulators into a random-effects meta-regression analysis to examine how they are associated with pooled frailty transition rates of three patterns (improving, worsening and staying the same). While age and gender were not significant in any models, a longer follow-up period was significantly associated with lower rates of improving frailty status (coefficient $=-0.09, \mathrm{p}=0.02$ ) and staying the same (coefficient $=-0.04$, $\mathrm{p}=0.02$ ) and higher rates of worsening frailty status (coefficient $=0.15, \mathrm{p}<0.01$ ). The extended follow-up period accounted for $19 \%, 6 \%$ and $34 \%$ of the total between-study variance of the improving, staying the same and worsening patterns, respectively. Among the nine frailty transition patterns, it was suggested that the younger study cohorts were, the more likely prefrail participants were to transition to robust $(\mathrm{p}=0.02)$ and that and longer follow-up was associated with the lower transition rate of remaining robust $(\mathrm{p}<0.01)$ and higher rates of transitions from robust to prefrail $(\mathrm{p}=0.03)$ and from robust to frail $(\mathrm{p}<0.01)$.

\section{DISCUSSION}

This study has shown pooled rates of frailty transition patterns among community-dwelling older people from data of 16 cohorts and examined how baseline frailty status, age, gender and follow-up period were associated with the patterns. More than half of the participants 
remained in the same frailty status, irrespective of gender and baseline frailty status. More participants worsened $(29.1 \%)$ rather than improved (13.7\%) frailty status. It was rare to transition from robust to frail or from frail to robust, both with a probability of about $3-4 \%$.

The high heterogeneity was observed in the three frailty patterns, and persisted in the nine frailty patterns and the subgroup analyses stratified by gender and study location (country), which may be due to between-study differences in the operationalization of the Fried phenotype components or on the inclusion/exclusion criteria for the study populations. Metaregression analyses suggested age and follow-up period were associated with frailty transition.

Previous studies have shown that people are more likely to be frail as they get older(Clegg et al., 2013) and to become frailer,(Espinoza et al., 2012; Lee et al., 2014; Trevisan et al., 2017) and younger people are more likely to improve frailty status.(Lee et al., 2014; Trevisan et al., 2017) Our meta-regression analysis examined how the mean age of the included cohorts is associated with the pooled rates of the three and nine frailty transition patterns and suggested that younger prefrail participants were more likely to transition back to robust. In metaregression models for other improving transition patterns, mean age was not statistically significant, which may be partly attributed to the fact that mean age was in a short range of 63.9-78.0 years old.

A gender difference in frailty is well known(Hubbard, 2015) and women tend to be more frail than men.(Collard et al., 2012; Kojima et al., 2017a) However, there is a paucity of evidence regarding the gender impact on frailty transitions and the findings of previous studies were inconsistent.(Borrat-Besson et al., 2013; Espinoza et al., 2012; Trevisan et al., 2017) One study showed women were more likely to both improve and worsen frailty status,(Trevisan et al., 2017) whereas gender was not significantly associated with frailty improvement in another study.(Espinoza et al., 2012) A study with a large number of participants from 12 European countries showed contradicting findings in which men were more likely to worsen frailty status when they were prefrail or frail at baseline and women were more likely to do so when robust at baseline.(Borrat-Besson et al., 2013) Pooled data of this review showed that compared with men, women were more likely to change frailty status either improving or worsening, rather than staying the same, which are in line with Trevisan and colleagues' findings.(Trevisan et al., 2017)

The follow-up period may have an impact on frailty transition patterns as people in general become more frail as they age.(Clegg et al., 2013; Collard et al., 2012) The shortest follow-up periods among the included studies were 1 year(Lanziotti Azevedo da Silva et al., 2015) and 1.5 years,(Gill et al., 2006; Xue, 2011) which seems sufficient time for older people to make changes in their frailty status. There is only one study among the included studies examining associations between frailty transitions and follow-up year.(Espinoza et al., 2012) This study assessed frailty transitions of 368 participants from the San Antonio Longitudinal Study of Aging cohort between baseline examination (1992-1996) and follow-up examination (20002001) over an average of 7.0 years, with the range 4.4-9.7 years. A one year increase in follow-up interval was associated with $30-40 \%$ higher risk of worsening frailty transition rather than remaining unchanged or improving in multivariable models.(Espinoza et al., 2012) In this review, data pooled from 16 studies showed that a longer follow-up period was associated with lower rates of improving and remaining the same and a higher rate of worsening in frailty transitions. This association is found to be more prominent among robust participants than in prefrail or frail participants in meta-regression analyses. 
The supplementary meta-analysis including death at follow-up highlights some differences in frailty transition patterns compared with the main analysis, although a precise comparison is not possible because different sets of studies were used. Mortality rates of those who were robust, prefrail and frail at baseline were $6.8 \%, 13.4 \%$ and $32.5 \%$, respectively. Among prefrail participants improvement was more common than progression towards frail $(23.1 \%$ versus $18.2 \%$ ) in the main meta-analysis not including death at follow-up. However, if death at follow-up was included as a worsening frailty transition from any frailty status at baseline, less prefrail participants improved to robust (17.8\%) and more worsened to frail $(15.5 \%)$ or death $(13.4 \%)$. Frail participants at baseline improved to robust $(3.3 \%)$ or prefrail $(40.3 \%)$ in the main meta-analysis while less frail participants improved to robust $(2.0 \%)$ and prefrail $(25.3 \%)$ in the supplementary meta-analysis including death at follow-up. As seen in the supplementary meta-analysis, frailty transition patterns are affected depending on whether or not including mortality, especially in prefrail and frail participants who are at higher risk of mortality than the robust.

First, this review included only studies that defined frailty by using the frailty phenotype criteria and did not consider studies with other frailty criteria. Even though the phenotype has been well validated and is the most commonly used frailty definition,(Buta et al., 2016) one of arguments is that although frailty is a multidimensional concept the phenotype criteria focus only on physical components and do not include other important factors, such as cognitive impairment.(Avila-Funes et al., 2009; Clegg et al., 2013) The Frailty Index of cumulative deficit model is one of multidimensional frailty definitions(Mitnitski et al., 2001) and the second most frequently used approach.(Buta et al., 2016) There are a few studies examining frailty transitions using the Frailty Index, all of which showed the frailty status of older people transitioned across different states and some actually improved over time.(Fallah et al., 2011; Liu et al., 2018; Mitnitski et al., 2007) Second, there was a high degree of heterogeneity observed across the studies. Therefore we used a random-effects meta-analysis and also conducted meta-regression analyses and found it was partially explained by differences in mean age and follow-up period of the cohorts. Third, as is often the case with frailty studies, all of the included studies applied different modifications to the original frailty phenotype criteria, which may have influenced the frailty classification.(Theou et al., 2015)

To the best of our knowledge, this review is the first study to complete a systematic review and meta-analysis on frailty transitions among community-dwelling older people, and has calculated pooled rates of various frailty transition patterns defined by the frailty phenotype, with and without death at follow-up. This review also conducted stratified meta-analyses and random-effects meta-regression analyses to explore how mean age, gender and follow-up period are associated with frailty transition rates. In addition to an extensive and reproducible search strategy using four electronic databases, we were able to add more studies by obtaining additional data necessary for meta-analysis from authors of potentially eligible studies, which yielded a total of 16 studies to be included. Our robust methodology also includes screening by two independent investigators, assessments of heterogeneity across the included studies, methodological quality and publication bias.

This review's findings on pooled rates of detailed natural frailty transitions in communitydwelling older people, overall as well as stratified by baseline frailty status and gender, contribute to further our understanding of the nature of frailty, and will be useful for researchers, clinicians and policy makers. In a clinical setting, especially in the care of elderly patients, it will help healthcare providers understand more about the dynamic nature of frailty 
and factors associated with directions of frailty courses. Researchers could use this information on frailty transitions in the targeting of new strategies for frailty prevention or intervention, and in understanding the expected outcomes of frailty in "usual care". It is now clearly confirmed that the frailty status of older people can change in either direction and reversion of frailty can occur. Therefore, it is plausible that appropriate interventions in a timely manner could promote the transition of prefrail or frail older people back to robust and potentially prevent related consequences. It also highlights the potential importance of targeting those earlier in the frailty pathway (the prefrail) of whom a large number have the potential to improve.

\subsection{Conclusion}

In summary, this review has found that older people experience dynamic changes in their frailty status in both improving and worsening directions. Half or more of older people remained in the same frailty status and approximately $10 \%$ improved and approximately $40 \%$ worsened their frailty status over a mean of 3.9 years. Given the fact that while approximately one quarter of prefrail older people improved to robust only $3 \%$ of frail older people did, early interventions should be considered for frailty.

\section{ACKNOWLEDGEMENTS}

We are grateful to the authors of the original articles who kindly shared additional data.(Borrat-Besson et al., 2013; Castrejon-Perez et al., 2017; Ensrud et al., 2010; GarciaEsquinas et al., 2016; Kim et al., 2017; Kojima et al., 2018a; Saum et al., 2017; Yu et al., 2015)

\section{FUNDING}

This study was supported by the Sasakawa Foundation grant (Grant Application No. 5364). GK is funded by a University College London (UCL) Overseas Research Scholarship. Neither funder had any influence on the study design and collection, analysis and interpretation of data, writing the manuscript and the decision to submit it for publication.

\section{REFERENCES}

Alencar, M.A., Dias, J.M.D., Figueiredo, L.C., Dias, R.C., 2015. Transitions in frailty status in community-dwelling older adults. Topics in Geriatric Rehabilitation 31, 105-112.

Avila-Funes, J.A., Amieva, H., Barberger-Gateau, P., Le Goff, M., Raoux, N., Ritchie, K., Carriere, I., Tavernier, B., Tzourio, C., Gutierrez-Robledo, L.M., Dartigues, J.F., 2009. Cognitive impairment improves the predictive validity of the phenotype of frailty for adverse health outcomes: the three-city study. Journal of the American Geriatrics Society 57, 453-461.

Borrat-Besson, C., Ryser, V.-A., Wernli, B., 2013. Active ageing and solidarity between generations in Europe: First results from SHARE after the economic crisis, 15 Transitions between frailty states-a European comparison. De Gruyter Publishers, Berlin, Germany.

Buta, B.J., Walston, J.D., Godino, J.G., Park, M., Kalyani, R.R., Xue, Q.L., Bandeen-Roche, K., Varadhan, R., 2016. Frailty assessment instruments: Systematic characterization of the uses and contexts of highly-cited instruments. Ageing research reviews 26, 5361.

Castrejon-Perez, R.C., Jimenez-Corona, A., Bernabe, E., Villa-Romero, A.R., Arrive, E., Dartigues, J.F., Gutierrez-Robledo, L.M., Borges-Yanez, S.A., 2017. Oral Disease and 3-Year Incidence of Frailty in Mexican Older Adults. The journals of gerontology. Series A, Biological sciences and medical sciences 72, 951-957. 
Cesari, M., Prince, M., Thiyagarajan, J.A., De Carvalho, I.A., Bernabei, R., Chan, P., Gutierrez-Robledo, L.M., Michel, J.P., Morley, J.E., Ong, P., Rodriguez Manas, L., Sinclair, A., Won, C.W., Beard, J., Vellas, B., 2016. Frailty: An Emerging Public Health Priority. Journal of the American Medical Directors Association 17, 188-192.

Clegg, A., Young, J., Iliffe, S., Rikkert, M.O., Rockwood, K., 2013. Frailty in elderly people. Lancet (London, England) 381, 752-762.

Collard, R.M., Boter, H., Schoevers, R.A., Oude Voshaar, R.C., 2012. Prevalence of frailty in community-dwelling older persons: a systematic review. Journal of the American Geriatrics Society 60, 1487-1492.

Ensrud, K.E., Ewing, S.K., Fredman, L., Hochberg, M.C., Cauley, J.A., Hillier, T.A., Cummings, S.R., Yaffe, K., Cawthon, P.M., 2010. Circulating 25-hydroxyvitamin D levels and frailty status in older women. The Journal of clinical endocrinology and metabolism 95, 5266-5273.

Espinoza, S.E., Jung, I., Hazuda, H., 2012. Frailty transitions in the San Antonio Longitudinal Study of Aging. Journal of the American Geriatrics Society 60, 652-660.

Fallah, N., Mitnitski, A., Searle, S.D., Gahbauer, E.A., Gill, T.M., Rockwood, K., 2011. Transitions in frailty status in older adults in relation to mobility: a multistate modeling approach employing a deficit count. Journal of the American Geriatrics Society 59, 524-529.

Feng, Z., Lugtenberg, M., Franse, C., Fang, X., Hu, S., Jin, C., Raat, H., 2017. Risk factors and protective factors associated with incident or increase of frailty among community-dwelling older adults: A systematic review of longitudinal studies. PloS one $12, \mathrm{e} 0178383$.

Fried, L.P., Tangen, C.M., Walston, J., Newman, A.B., Hirsch, C., Gottdiener, J., Seeman, T., Tracy, R., Kop, W.J., Burke, G., McBurnie, M.A., 2001. Frailty in older adults: evidence for a phenotype. The journals of gerontology. Series A, Biological sciences and medical sciences 56, M146-156.

Garcia-Esquinas, E., Rahi, B., Peres, K., Colpo, M., Dartigues, J.F., Bandinelli, S., Feart, C., Rodriguez-Artalejo, F., 2016. Consumption of fruit and vegetables and risk of frailty: a dose-response analysis of 3 prospective cohorts of community-dwelling older adults. The American journal of clinical nutrition 104, 132-142.

Gill, T.M., Gahbauer, E.A., Allore, H.G., Han, L., 2006. Transitions between frailty states among community-living older persons. Archives of internal medicine 166, 418-423.

Hubbard, R.E., 2015. Sex Differences in Frailty. Interdisciplinary topics in gerontology and geriatrics 41, 41-53.

Kim, M., Suzuki, T., Kojima, N., Yoshida, H., Yoshida, Y., Hirano, H., Won, C.W., Kim, H., 2017. Association Between Serum beta2 -Microglobulin Levels and Prevalent and Incident Physical Frailty in Community-Dwelling Older Women. Journal of the American Geriatrics Society 65, e83-e88.

Kojima, G., 2015a. Frailty as a Predictor of Future Falls Among Community-Dwelling Older People: A Systematic Review and Meta-Analysis. Journal of the American Medical Directors Association 16, 1027-1033.

Kojima, G., 2015b. Prevalence of Frailty in Nursing Homes: A Systematic Review and MetaAnalysis. Journal of the American Medical Directors Association 16, 940-945.

Kojima, G., 2016a. Frailty as a predictor of fractures among community-dwelling older people: A systematic review and meta-analysis. Bone 90, 116-122.

Kojima, G., 2016b. Frailty as a predictor of hospitalisation among community-dwelling older people: a systematic review and meta-analysis. Journal of epidemiology and community health 70, 722-729. 
Kojima, G., 2017a. Frailty as a predictor of disabilities among community-dwelling older people: a systematic review and meta-analysis. Disability and Rehabilitation 39, 1897-1908.

Kojima, G., 2017b. Frailty significantly increases the risk of fractures among middle-aged and older people. Evidence-based nursing 20, 119-120.

Kojima, G., 2017c. Prevalence of frailty in end-stage renal disease: a systematic review and meta-analysis. International urology and nephrology 49, 1989-1997.

Kojima, G., 2018a. Frailty as a Predictor of Emergency Department Utilization among Community-Dwelling Older People: A Systematic Review and Meta-Analysis. Journal of the American Medical Directors Association.

Kojima, G., 2018b. Frailty as a Predictor of Nursing Home Placement among CommunityDwelling Older Adults: A Systematic Review and Meta-analysis. Journal of Geriatric Physical Therapy 41, 42-48.

Kojima, G., 2018c. Frailty Defined by FRAIL Scale as a Predictor of Mortality: A Systematic Review and Meta-analysis. Journal of the American Medical Directors Association $19,480-483$.

Kojima, G., 2018d. Quick and Simple FRAIL Scale Predicts Incident Activities of Daily Living (ADL) and Instrumental ADL (IADL) Disabilities: A Systematic Review and Meta-analysis. Journal of the American Medical Directors Association.

Kojima, G., Iliffe, S., Jivraj, S., Liljas, A., Walters, K., 2018a. Does current smoking predict future frailty? The English longitudinal study of ageing. Age and ageing 47, 126-131.

Kojima, G., Iliffe, S., Jivraj, S., Walters, K., 2016a. Association between frailty and quality of life among community-dwelling older people: a systematic review and metaanalysis. Journal of epidemiology and community health 70, 716-721.

Kojima, G., Iliffe, S., Morris, R.W., Taniguchi, Y., Kendrick, D., Skelton, D.A., Masud, T., Bowling, A., 2016b. Frailty predicts trajectories of quality of life over time among British community-dwelling older people. Quality of life research : an international journal of quality of life aspects of treatment, care and rehabilitation 25, 1743-1750.

Kojima, G., Iliffe, S., Taniguchi, Y., Shimada, H., Rakugi, H., Walters, K., 2017a. Prevalence of frailty in Japan: A systematic review and meta-analysis. Journal of epidemiology 27, 347-353.

Kojima, G., Iliffe, S., Walters, K., 2018b. Frailty index as a predictor of mortality: a systematic review and meta-analysis. Age and ageing 47, 193-200.

Kojima, G., Kendrick, D., Skelton, D.A., Morris, R.W., Gawler, S., Iliffe, S., 2015. Frailty predicts short-term incidence of future falls among British community-dwelling older people: a prospective cohort study nested within a randomised controlled trial. BMC geriatrics 15, 155.

Kojima, G., Liljas, A., Iliffe, S., Walters, K., 2017b. Prevalence of Frailty in Mild to Moderate Alzheimer's Disease: A Systematic Review and Meta-analysis. Current Alzheimer research 14, 1256-1263.

Kojima, G., Taniguchi, Y., Kitamura, A., Shinkai, S., 2018c. Are the Kihon Checklist and the Kaigo-Yobo Checklist compatible with the Frailty Index? Journal of the American Medical Directors Association 19, 797-800.

Lanziotti Azevedo da Silva, S., Campos Cavalcanti Maciel, A., de Sousa Maximo Pereira, L., Domingues Dias, J.M., Guimaraes de Assis, M., Correa Dias, R., 2015. Transition Patterns of Frailty Syndrome in Comunity-Dwelling Elderly Individuals: A Longitudinal Study. The Journal of frailty \& aging 4, 50-55.

Lee, J.S., Auyeung, T.W., Leung, J., Kwok, T., Woo, J., 2014. Transitions in frailty states among community-living older adults and their associated factors. Journal of the American Medical Directors Association 15, 281-286. 
Liu, Z.Y., Wei, Y.Z., Wei, L.Q., Jiang, X.Y., Wang, X.F., Shi, Y., Hai, H., 2018. Frailty transitions and types of death in Chinese older adults: a population-based cohort study. Clinical interventions in aging 13, 947-956.

Mello Ade, C., Engstrom, E.M., Alves, L.C., 2014. Health-related and socio-demographic factors associated with frailty in the elderly: a systematic literature review. Cadernos de saude publica 30, 1143-1168.

Mitnitski, A., Song, X., Rockwood, K., 2007. Improvement and decline in health status from late middle age: modeling age-related changes in deficit accumulation. Experimental gerontology 42, 1109-1115.

Mitnitski, A.B., Mogilner, A.J., Rockwood, K., 2001. Accumulation of deficits as a proxy measure of aging. TheScientificWorldJournal 1, 323-336.

Moher, D., Liberati, A., Tetzlaff, J., Altman, D.G., 2009. Preferred reporting items for systematic reviews and meta-analyses: the PRISMA statement. BMJ (Clinical research ed.) $339, \mathrm{~b} 2535$.

Morley, J.E., 2017. Frailty Fantasia. Journal of the American Medical Directors Association $18,813-815$.

Morley, J.E., Vellas, B., van Kan, G.A., Anker, S.D., Bauer, J.M., Bernabei, R., Cesari, M., Chumlea, W.C., Doehner, W., Evans, J., Fried, L.P., Guralnik, J.M., Katz, P.R., Malmstrom, T.K., McCarter, R.J., Gutierrez Robledo, L.M., Rockwood, K., von Haehling, S., Vandewoude, M.F., Walston, J., 2013. Frailty consensus: a call to action. Journal of the American Medical Directors Association 14, 392-397.

Nyaga, V.N., Arbyn, M., Aerts, M., 2014. Metaprop: a Stata command to perform metaanalysis of binomial data. Archives of public health $=$ Archives belges de sante publique $72,39$.

Ottenbacher, K.J., Graham, J.E., Al Snih, S., Raji, M., Samper-Ternent, R., Ostir, G.V., Markides, K.S., 2009. Mexican Americans and frailty: findings from the Hispanic established populations epidemiologic studies of the elderly. American journal of public health 99, 673-679.

Pollack, L.R., Litwack-Harrison, S., Cawthon, P.M., Ensrud, K., Lane, N.E., Barrett-Connor, E., Dam, T.T., 2017. Patterns and Predictors of Frailty Transitions in Older Men: The Osteoporotic Fractures in Men Study. Journal of the American Geriatrics Society 65, 2473-2479.

Saum, K.U., Schottker, B., Meid, A.D., Holleczek, B., Haefeli, W.E., Hauer, K., Brenner, H., 2017. Is Polypharmacy Associated with Frailty in Older People? Results From the ESTHER Cohort Study. Journal of the American Geriatrics Society 65, e27-e32.

Stroup, D.F., Berlin, J.A., Morton, S.C., Olkin, I., Williamson, G.D., Rennie, D., Moher, D., Becker, B.J., Sipe, T.A., Thacker, S.B., 2000. Meta-analysis of observational studies in epidemiology: a proposal for reporting. Meta-analysis Of Observational Studies in Epidemiology (MOOSE) group. Jama 283, 2008-2012.

Theou, O., Cann, L., Blodgett, J., Wallace, L.M., Brothers, T.D., Rockwood, K., 2015. Modifications to the frailty phenotype criteria: Systematic review of the current literature and investigation of 262 frailty phenotypes in the Survey of Health, Ageing, and Retirement in Europe. Ageing research reviews 21, 78-94.

Trevisan, C., Veronese, N., Maggi, S., Baggio, G., Toffanello, E.D., Zambon, S., Sartori, L., Musacchio, E., Perissinotto, E., Crepaldi, G., Manzato, E., Sergi, G., 2017. Factors Influencing Transitions Between Frailty States in Elderly Adults: The Progetto Veneto Anziani Longitudinal Study. Journal of the American Geriatrics Society 65, 179-184. 
Wells, G.A., Shea, D., O'Connell, D., Peterson, J., Welch, V., Losos, M., Tugwell, P., The Newcastle-Ottawa Scale (NOS) for assessing the quality of nonrandomised studies in meta-analyses.

Xue, Q.L., 2011. The frailty syndrome: definition and natural history. Clinics in geriatric medicine 27, 1-15.

Yu, R., Tang, N., Leung, J., Woo, J., 2015. Telomere length is not associated with frailty in older Chinese elderly: Cross-sectional and longitudinal analysis. Mechanisms of ageing and development 152, 74-79. 
Figure 1. Flow chart of systematic literature review.

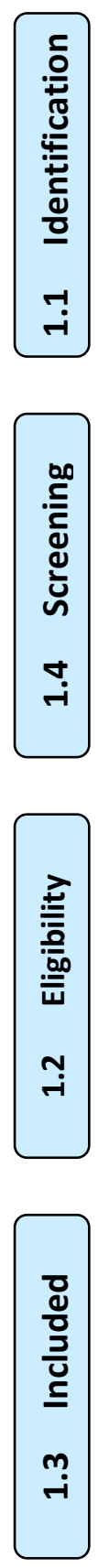

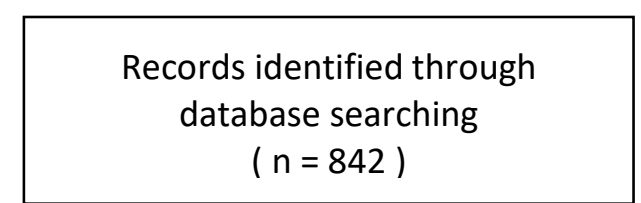

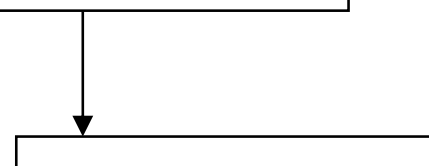

Records after duplicates removed

$(n=504)$
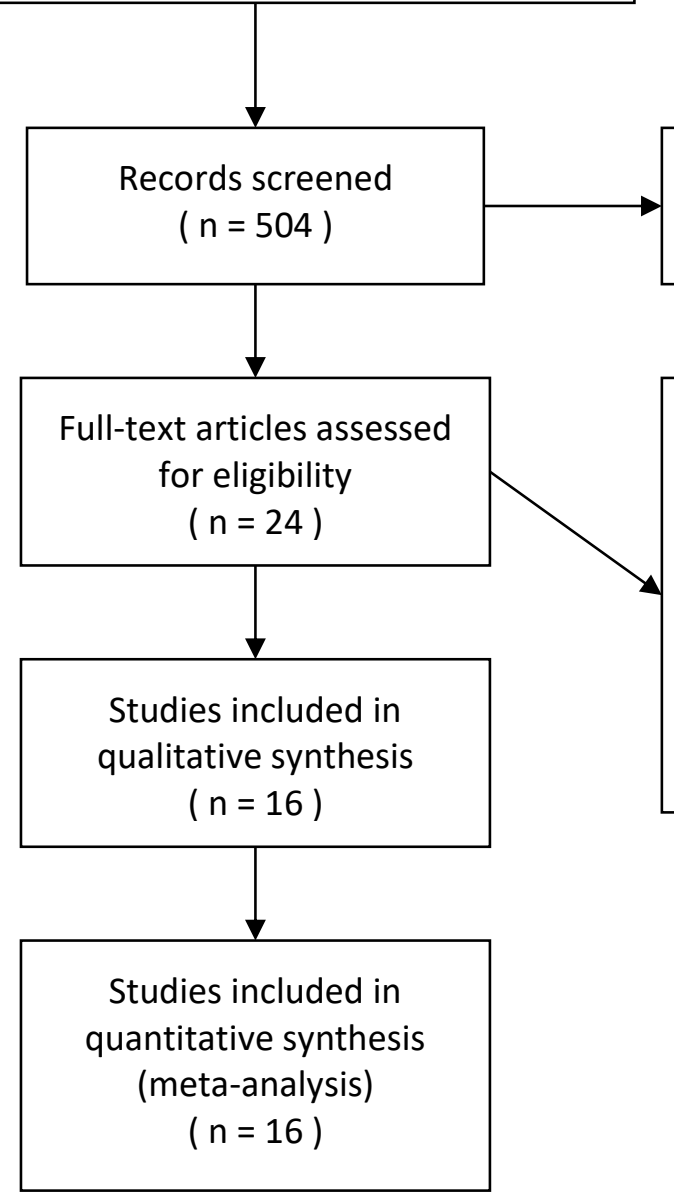

Records excluded

$(n=480)$

Full-text articles excluded, with reasons $(n=8)$

- Did not provide sufficient data $(n=5)$

- Used the same cohorts

$(\mathrm{n}=2)$

- Used 4-item frailty phenotype criteria $(n=1)$ 
Figure 2. Forest plots of frailty transition rates of (A) improvement, (B) worsening and (C) staying the same.

A

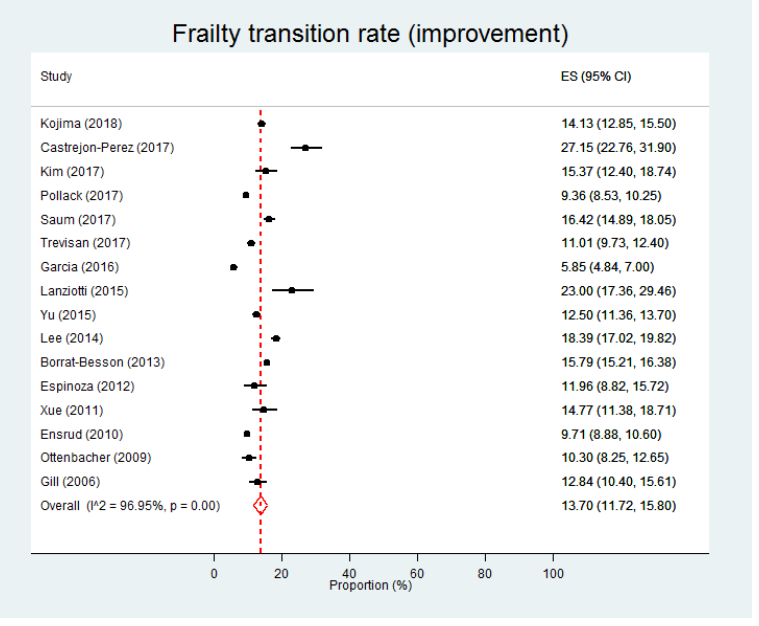

B

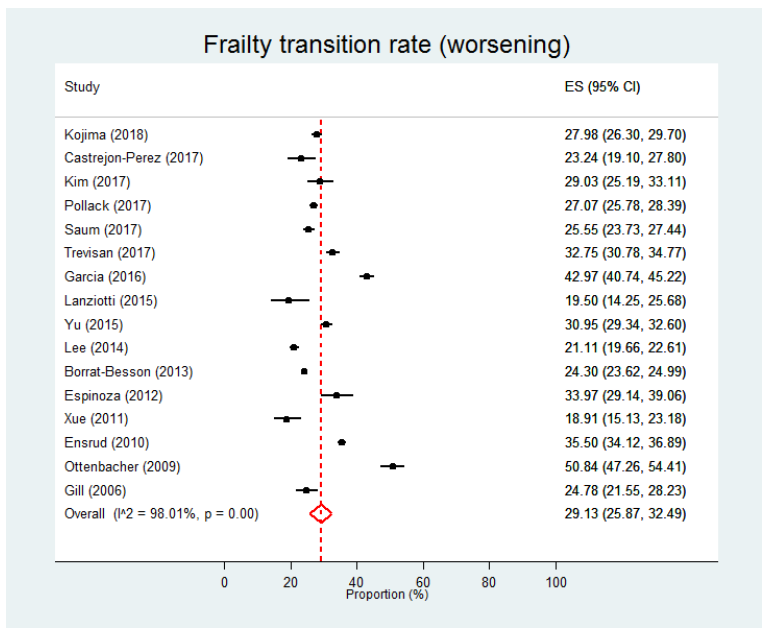

$\mathrm{C}$

Frailty transition rate (staying the same)

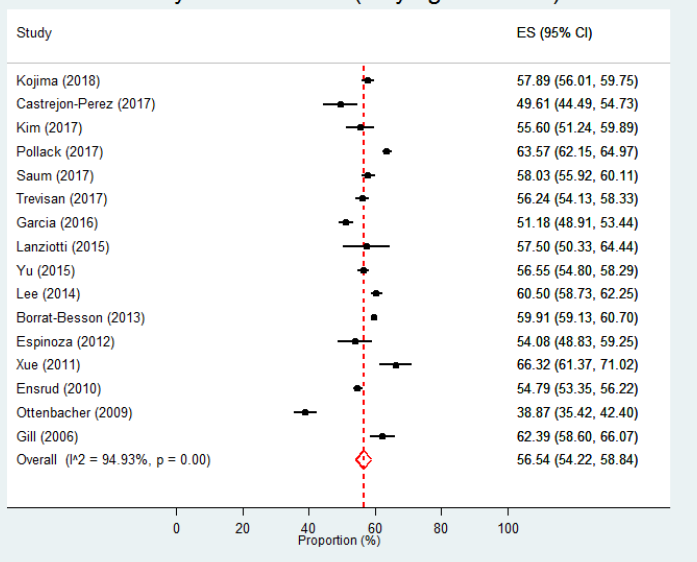


Figure 3. Nine frailty transition patterns according to baseline frailty status in overall (16 studies), women-only (11 studies) and men-only (9 studies) samples.

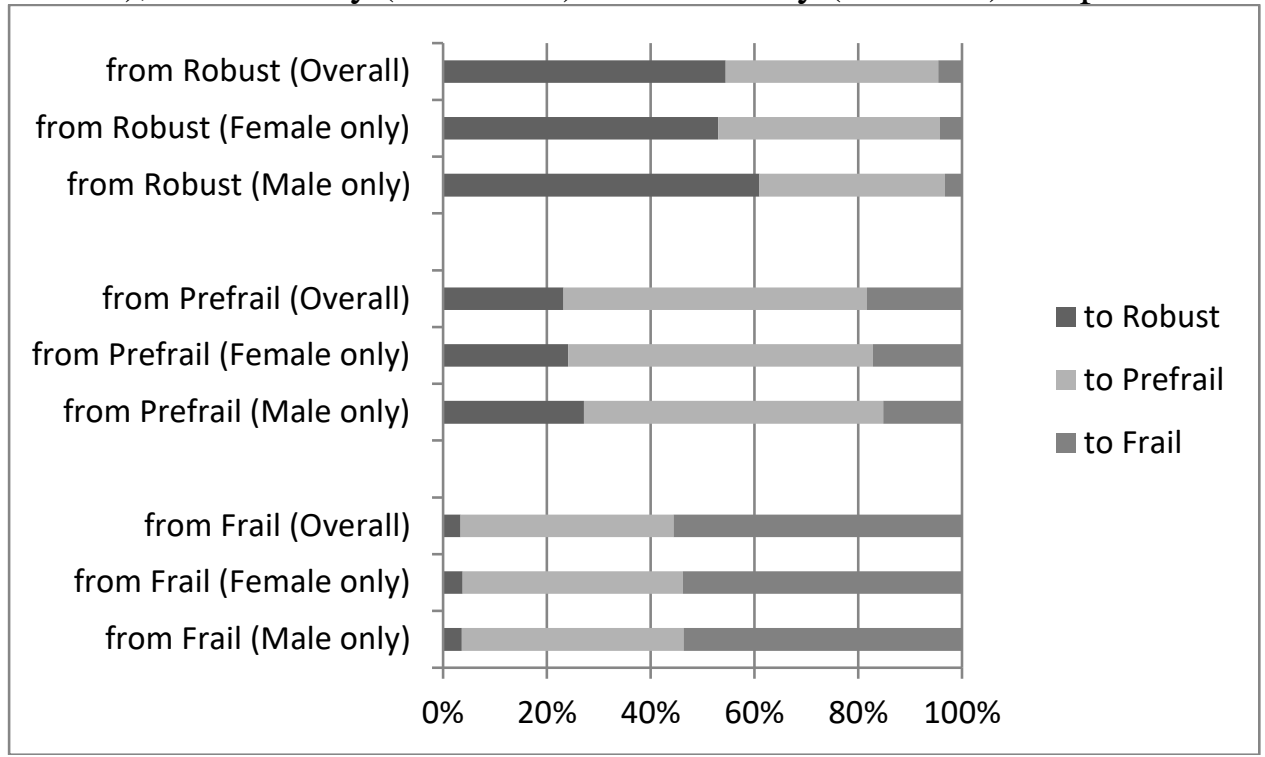


Table 1. Summary of the studies on frailty transitions among community-dwelling older people.

\begin{tabular}{|c|c|c|c|c|c|c|c|c|}
\hline $\begin{array}{l}\text { First author/Year } \\
\text { Study (Location) }\end{array}$ & $\begin{array}{l}\text { Sample } \\
\text { size* }\end{array}$ & Improved & Worsened & $\begin{array}{l}\text { Stayed the } \\
\text { same }\end{array}$ & Died* & $\begin{array}{l}\text { Female } \\
\qquad(\%)\end{array}$ & $\begin{array}{c}\text { Age } \\
\text { (range) }\end{array}$ & $\begin{array}{l}\text { Follow-up } \\
\text { period }\end{array}$ \\
\hline $\begin{array}{l}\text { Kojima } 2018 \\
\text { ELSA (UK) }\end{array}$ & 2731 & 386 & 764 & 1581 & Not reported & $55.5 \%$ & $\begin{array}{c}69.6 \\
(>=60)\end{array}$ & 4 years \\
\hline $\begin{array}{l}\text { Castrejon-Perez } 2017 \\
\text { Coyoacan Cohort Study } \\
\text { (Mexico) }\end{array}$ & 383 & 104 & 89 & 190 & Not reported & $54.0 \%$ & $\begin{array}{c}77.9 \\
(>=70)\end{array}$ & 3 years \\
\hline $\begin{array}{l}\text { Kim } 2017 \\
\text { Otasha-Kenshin study } \\
\text { (Japan) }\end{array}$ & 527 & 81 & 153 & 293 & Not reported & $100 \%$ & $\begin{array}{c}78.0 \\
(>=75)\end{array}$ & 4 years \\
\hline $\begin{array}{l}\text { Pollack } 2017 \\
\text { MrOS study (USA) }\end{array}$ & 4518 & 423 & 1223 & 2872 & 1223 & $0 \%$ & $\begin{array}{c}73.4 \\
(>=65)\end{array}$ & 4.6 years \\
\hline $\begin{array}{l}\text { Saum } 2017 \\
\text { ESTHER Cohort Study } \\
\text { (Germany) }\end{array}$ & 2180 & 358 & 557 & 1265 & Not reported & $52.2 \%$ & $\begin{array}{c}69.6 \\
(57-82)\end{array}$ & 3 years \\
\hline $\begin{array}{l}\text { Trevisan } 2017 \\
\text { Pro. V.A. (Italy) }\end{array}$ & 2180 & 240 & 714 & 1226 & 745 & $63.3 \%$ & $\begin{array}{c}74.4 \\
(>=65)\end{array}$ & 4.4 years \\
\hline $\begin{array}{l}\text { Garcia-Esquinas } 2016 \\
\text { Seniors-ENRICA (Spain) }\end{array}$ & 1872 & 112 & 822 & 979 & Not reported & $51.6 \%$ & $\begin{array}{c}68.7 \\
(>=60)\end{array}$ & 3.5 years \\
\hline $\begin{array}{l}\text { Lanziotti } 2015 \\
\text { FIBRA (Brazil) }\end{array}$ & 200 & 46 & 39 & 115 & Not reported & $68.0 \%$ & $\begin{array}{c}73.7 \\
(>=65)\end{array}$ & 1 year \\
\hline $\begin{array}{l}\text { Yu } 2015 \\
\text { Mr. and Ms. Os Study } \\
\text { (China) }\end{array}$ & 3153 & 394 & 976 & 1783 & Not reported & $50.3 \%$ & $\begin{array}{c}72.5 \\
(>=65)\end{array}$ & 4 years \\
\hline $\begin{array}{l}\text { Lee } 2014 \\
\text { (China) }\end{array}$ & 3018 & 555 & 637 & 1826 & 323 & $49.7 \%$ & $\begin{array}{c}73.6 \\
(>=65)\end{array}$ & 2 years \\
\hline $\begin{array}{l}\text { Borrat-Besson } 2013 \\
\text { SHARE (12 European } \\
\text { countries**) }\end{array}$ & 15127 & 2388 & 3676 & 9063 & 649 & $54.1 \%$ & $\begin{array}{c}63.9 \\
(>=50)\end{array}$ & 4 years \\
\hline $\begin{array}{l}\text { Espinoza } 2012 \\
\text { SALSA (USA) } \\
\end{array}$ & 368 & 44 & 125 & 199 & 124 & $55.1 \%$ & $\begin{array}{c}69.6 \\
(>=65)\end{array}$ & 7 years \\
\hline $\begin{array}{l}\text { Xue } 2011 \\
\text { WHAS II (USA) }\end{array}$ & 386 & 57 & 73 & 256 & 7 & $100 \%$ & $\begin{array}{c}74.5 \\
(70-79) \\
\end{array}$ & 1.5 years \\
\hline $\begin{array}{l}\text { Ensrud } 2010 \\
\text { SOF (USA) }\end{array}$ & 4685 & 455 & 1663 & 2567 & Not reported & $100 \%$ & $\begin{array}{c}76.0 \\
(>=69)\end{array}$ & 4.5 years \\
\hline $\begin{array}{l}\text { Ottenbacher } 2009 \\
\text { HEPESE (USA) }\end{array}$ & 777 & 80 & 395 & 302 & 893 & $62.5 \%$ & $\begin{array}{c}72.5 \\
(>=65)\end{array}$ & 10 years \\
\hline $\begin{array}{l}\text { Gill } 2006 \\
\text { Precipitating Events } \\
\text { Project (USA) }\end{array}$ & 670 & 86 & 166 & 418 & 49 & $64.6 \%$ & $\begin{array}{c}78.4 \\
(>=70)\end{array}$ & 1.5 years \\
\hline
\end{tabular}

* Sample size not including those who died during follow-up

** Austria, Belgium, Czech, Denmark, France, Germany, Italy, Netherlands, Poland, Spain,

Sweden, Switzerland,

ELSA: English Longitudinal Study of Ageing

FIBRA: Rede de Estudos da Fragilidade de Idosos Brasileiros

HEPESE: Hispanic Established Populations for Epidemiologic Studies of the Elderly

MrOS: Osteoporotic Fractures in Men Study

Pro. V.A.: Progetto Veneto Anziani study

SALSA: San Antonio Longitudinal Study of Aging

SHARE: Survey of Health, Ageing and Retirement in Europe

SOF: Study of Osteoporotic Fractures

WHAS: Women's Health and Aging Studies

WHI-OS: Women's Health Initiative Observational Study 
Table 2. Transition rates of frailty status (improvement, progression and staying the same) in overall (16 studies), women-only (11 studies), men-only (9 studies) and death-including (9 studies) samples.

\begin{tabular}{|c|c|c|c|c|c|}
\hline Frailty transition & $\begin{array}{c}\text { Overall } \\
(16 \text { studies })\end{array}$ & $\begin{array}{c}\text { Female } \\
(11 \text { studies })\end{array}$ & $\begin{array}{c}\text { Male } \\
(9 \text { studies })\end{array}$ & $\begin{array}{c}\text { p for gender } \\
\text { difference }\end{array}$ & $\begin{array}{c}\text { Including death } \\
(9 \text { studies })\end{array}$ \\
\hline Improving & $13.7 \%(11.7-15.8 \%)$ & $14.7 \%(12.3-17.4 \%)$ & $12.6 \%(9.9-15.6 \%)$ & 0.28 & $10.9 \%(8.0-14.2 \%)$ \\
\hline Worsening & $29.1 \%(25.9-32.5 \%)$ & $28.5 \%(24.4-32.7 \%)$ & $28.0 \%(24.9-31.2 \%)$ & 0.87 & $37.8 \%(27.6-48.5 \%)$ \\
\hline Staying the same & $56.5 \%(54.2-58.8 \%)$ & $55.9 \%(54.0-57.8 \%)$ & $59.1 \%(57.2-61.1 \%)$ & 0.02 & $50.3 \%(41.9-58.7 \%)$ \\
\hline & & & & & \\
\hline Robust at baseline & & & & & \\
\hline to Robust & $54.0 \%(48.8-59.1 \%)$ & $52.5 \%(45.8-59.2 \%)$ & $60.5 \%(56.8-64.2 \%)$ & 0.04 & $53.6 \%(43.9-63.2 \%)$ \\
\hline to Prefrail & $40.6 \%(36.7-44.7 \%)$ & $42.4 \%(37.0-47.9 \%)$ & $35.5 \%(32.0-39.2 \%)$ & 0.04 & $31.9 \%(29.8-34.1 \%)$ \\
\hline to Frail & $4.5 \%(3.2-6.1 \%)$ & $4.2 \%(2.6-6.2 \%)$ & $3.3 \%(2.5-4.3 \%)$ & 0.34 & $3.3 \%(1.9-5.1 \%)$ \\
\hline to Death & - & - & - & - & $6.8 \%(2.1-14.0 \%)$ \\
\hline Prefrail at baseline & & & & & \\
\hline to Robust & $23.1 \%(18.8-27.6 \%)$ & $23.9 \%(18.7-29.5 \%)$ & $27.0 \%(20.7-33.8 \%)$ & 0.46 & $17.8 \%(11.6-25.1 \%)$ \\
\hline to Prefrail & $58.2 \%(55.6-60.7 \%)$ & $58.3 \%(55.1-61.4 \%)$ & $57.5 \%(53.2-61.7 \%)$ & 0.77 & $48.3 \%(40.8-55.8 \%)$ \\
\hline to Frail & $18.2 \%(14.9-21.7 \%)$ & $17.1 \%(12.6-22.2 \%)$ & $15.1 \%(12.1-18.4 \%)$ & 0.50 & $15.5 \%(12.2-19.2 \%)$ \\
\hline to Death & - & - & - & - & $13.4 \%(5.1-24.7 \%)$ \\
\hline Frail at baseline & & & & & \\
\hline to Robust & $3.3 \%(1.6-5.5 \%)$ & $3.7 \%(2.0-5.6 \%)$ & $3.5 \%(0.3-8.7 \%)$ & 0.72 & $2.0 \%(0.2-4.8 \%)$ \\
\hline to Prefrail & $40.3 \%(34.6-46.1 \%)$ & $41.8 \%(34.8-49.0 \%)$ & $41.6 \%(36.5-46.8 \%)$ & 0.99 & $25.3 \%(16.6-35.2 \%)$ \\
\hline to Frail & $54.5 \%(47.6-61.3 \%)$ & $53.1 \%(45.0-61.1 \%)$ & $52.2 \%(41.6-62.7 \%)$ & 0.88 & $33.6 \%(22.0-46.2 \%)$ \\
\hline to Death & - & - & - & - & $32.5 \%(17.3-49.8 \%)$ \\
\hline
\end{tabular}

